\title{
Gallstone Frequency in Patients with Helicobacter pylori Gastritis
}

\author{
Behnaz Eslami ${ }^{1}$, Majid Iranshahi ${ }^{2}$, Latif Gachkar ${ }^{1}{ }^{1}$ and Fahimeh Hadavand ${ }^{1,{ }^{*}}$ \\ ${ }^{1}$ Infectious Diseases and Tropical Medicine Research Center, Shahid Beheshti University of Medical Sciences, Tehran, Iran \\ ${ }^{2}$ Shahid Beheshti University of Medical Sciences, Tehran, Iran \\ "Corresponding author: Infectious Diseases and Tropical Medicine Research Center, Shahid Beheshti University of Medical Sciences, Tehran, Iran. Tel: +98-2122439968, Email: \\ fahimehadavand140@gmail.com
}

Received 2020 January 08; Revised 2021 March 19; Accepted 2021 April 11.

\begin{abstract}
Background: Identification of the causes of gallstone would result in better planning for the prevention of this disease. One of the proposed risk factors for this problem is Helicobacter pylori (H. pylori) infection.

Objectives: The purpose of this study was to determine the incidence rate of gallstone in patients with $H$. pylori gastritis.

Methods: This was an observational study performed as a descriptive-comparative cross-sectional survey. We enrolled 169 consecutive patients with H. pylori gastritis admitted to Imam-Hossein Hospital, Tehran, Iran, in 2018, and gallstone frequency in them was determined and compared with other variables.

Results: Overall, 14 (8.3\%) patients had gallstone, and all the patients had H. pylori gastritis. There was no significant association between gallstone and $H$. pylori gastritis $(\mathrm{P}=0.561)$.

Conclusions: It may be concluded that gallstone frequency in patients with $H$. pylori gastritis is low, and there is no significant association between these two conditions.
\end{abstract}

Keywords: Gallstone, Helicobacter pylori, Gastritis

\section{Background}

Gallstone is a common problem with a prevalence rate ranging from $11 \%$ to $36 \%$ (1). The incidence rate of this problem is related to age, sex, and ethnicity, with a higher rate among female subjects (1). The association between gallstone and Helicobacter pylori (H. pylori) infection is controversial (1-6). Determining the association between gallstone and H. pylori infection would help to better plan preventive programs $(2,7-10)$. Cholecystitis is a common surgical procedure usually due to gallstone (11). Female gender, older age, and obesity are important risk factors for cholecystitis $(11,12)$, but it may be seen without gallstone in nearly $10 \%$ of cases (13). Gallstone is related to both environmental and genetic factors (14). Gallstone may even be seen in asymptomatic patients, and further workup with a special focus on the etiological factors is required $(15,16)$. Helicobacter pylori is an important infectious factor besides the other related diseases such as peptic ulcer, dyspepsia, and cancer (17); it is observed in 70.1\%, and $86.2 \%$ of patients with gastritis and gastric ulcer, respectively (18), and positive antibody is seen in 86.3 - 91\% of Iranian patients (19).

\section{Objectives}

Helicobacter pylori eradication can result in decreased rate and severity of gastrointestinal symptoms, especially dyspepsia, and would help to improve the quality of life $(20,21)$. Hence, the purpose of this study was to determine gallstone frequency in patients with H. pylori gastritis.

\section{Methods}

This observational study was performed as a descriptive-comparative cross-sectional survey. We participated 169 consecutive patients with $H$. pylori gastritis that had dyspepsia and epigastric pain and were admitted to Imam-Hossein Hospital, Tehran, Iran, in 2018; the required data was recorded in a checklist. The exclusion criteria were the use of antibiotics with anti-H. pylori effects such as metronidazole, ciprofloxacin, levofloxacin, amoxicillin, bismuth, tetracycline, and clarithromycin, besides PPI use.

This study was approved by the local ethics committee with the code of ethics BMSU13971617. Informed consent was not required, but confidentiality of the data was 
respected. All the ethical considerations were adhered to, and we had no intervention in this study. Biopsy samples were assessed to establish $H$. pylori infection and gastritis, and they were stained by Hematoxylin and Eosin. In positive cases for $\mathrm{H}$. pylori infection, gallstone frequency rate was determined by ultrasound assessment and compared with other variables.

Data analysis was performed by SPSS version 25.0. The numerical data was reported as mean and standard deviation, and frequency and percentage were reported for categorical variables. chi-square test and Fisher's exact test were run to analyze the data. A P-value of less than 0.05 . was considered significant.

\section{Results}

Among the subjects, $64.5 \%$ were female, $18.9 \%$ were under 40 years old, and $23.7 \%$ were over 60 years old. The residence location was cities other than Tehran in $23.1 \%$ of the patients. Body mass index (BMI) was underweight, normal, overweight, and obese in $3 \%, 37.3 \%, 24.3 \%$, and $35.3 \%$, respectively. Gallstone was diagnosed in $8.3 \%$ of cases, family history was positive in $28(16.6 \%)$ of cases, and gastritis was mild, moderate, and severe in $21.3 \%, 65.7 \%$, and $13 \%$ of cases respectively. Among the subjects, 85 (50.3\%) patients had high amounts of H. pylori. Gallstone history was positive in $5(3 \%)$ patients.

As shown in Table 1, gender and gallstone were interrelated $(\mathrm{P}=0.002)$. Also, age was related to gallstone $(\mathrm{P}=$ $0.029)$. There was no significant association between gallstone and residence location $(\mathrm{P}=1.000)$, BMI $(\mathrm{P}=1.000)$, and gastritis severity $(\mathrm{P}=0.176)$.

There was a significant association between gallstone and family history $(\mathrm{P}=0.014)$ and between gallstone and self-history of gallstone. However, there was no significant association between gallstone and H. pylori gastritis $(\mathrm{P}=$ $0.561)$.

\section{Discussion}

In this study, gallstone frequency in patients with $H$. pylori gastritis was determined. We also evaluated the factors contributing to gallstone and the treatment of gastritis due to H. pylori that may prevent stone formation and subsequent surgical complications. In this study, $8.3 \%$ of the patients with $H$. pylori gastritis had gallstone in ultrasound assessment. However, the severity of gastritis was not related to gallstone. Older age, female gender, and gallstone history were related to gallstone in the current study.

\begin{tabular}{|c|c|c|c|}
\hline & Positive $^{\mathrm{a}}$ & Negative $^{a}$ & P-Value \\
\hline Gender & & & 0.002 \\
\hline Female & $14(100.0)$ & $95(61.3)$ & \\
\hline Male & $0(0)$ & $60(38.7)$ & \\
\hline Age group & & & 0.029 \\
\hline $20-30$ & $0(0)$ & $8(5.2)$ & \\
\hline $31-40$ & $3(21.4)$ & $21(13.5)$ & \\
\hline $41-50$ & $0(0)$ & $27(17.4)$ & \\
\hline $51-60$ & $11(78.6)$ & $59(38.1)$ & \\
\hline $61-70$ & $0(0)$ & $26(16.8)$ & \\
\hline $71-80$ & $0(0)$ & $14(9.0)$ & \\
\hline Family history & & & 0.014 \\
\hline Positive & $6(42.9)$ & $22(14.2)$ & \\
\hline Negative & $8(57.1)$ & $133(85.8)$ & \\
\hline Self-gallstone history & & & 0.0001 \\
\hline Positive & $5(35.7)$ & - & \\
\hline Negative & $9(64.3)$ & $155(100)$ & \\
\hline Helicobacter pylori & & & 0.561 \\
\hline High & $6(42.9)$ & $79(51.0)$ & \\
\hline Low & $8(57.1)$ & $76(49.0)$ & \\
\hline
\end{tabular}

${ }^{\mathrm{a}}$ Values are expressed as No. (\%).

The study by Attaallah et al. (1) revealed that 37\% of patients with symptomatic gallstone had H. pylori infection, but this rate was lower in our study. Zhang et al. (2) reported that the incidence rates of gallstone in patients with positive helicobacter, eradicated helicobacter, and negative helicobacter status were 9.47\%, 9.02\%, and $8.46 \%$, respectively, showing no significant association. Sabbaghian et al. (3) studied 36 patients under cholecystectomy and noted that $33.3 \%$ were positive for $H$.pylori in PCR; this rate was lower in our study.

The study by Lee et al. (4) among 58 cases under cholecystectomy found that $H$. pylori was positive in four cases with gallstones, six cases with biliary secretions, and five patients with positive biliary tissue. The reported rates were higher than those obtained in our study. Monstein et al. (5) reported that $55 \%$ of patients with cholesterol gallstone had a positive status for $H$. pylori, this rate was higher in comparison with our finding. Takahashi et al. (6) reported that the prevalence rates of gallstone in cases with negative helicobacter status, eradicated conditions, and positive cases were $3.81 \%, 4.37 \%$, and $6.08 \%$, respectively, while the rate in our study was higher. 
The study by Stathopoulos et al. (7) showed that 20.54\% of cases with gallstone had positive results for $H$. pylori infection in gastric biopsy samples, which was higher than our finding. Deeba et al. (8) studied 75 patients with gallstone symptoms, which showed that IgG was positive against $H$. pylori; this rate was higher than our results. Abro et al. (9) demonstrated that H.pylori infection was observed in the biliary tissue of 55\% of cases with chronic cholecystitis. Fikry et al. (10) reported a contributing rate of $63 \%$, which is higher than our obtained results.

In sum, gallstone frequency in patients with $H$. pylori gastritis is low, and there is no statistically significant association between these two conditions. However, further studies with larger sample sizes are required to corroborate our results.

\section{Acknowledgments}

We wish to thanks all the individuals who participated in this study.

\section{Footnotes}

Authors' Contribution: All authors had an equal contribution.

Conflict of Interests: There were no conflicts of interest.

Ethical Approval: This study was approved by the local ethics committee with the code of ethics BMSU13971617.

Funding/Support: There was no funding/support in this study.

\section{References}

1. Attaallah W, Yener N, Ugurlu MU, Manukyan M, Asmaz E, Aktan AO. Gallstones and Concomitant Gastric Helicobacter pylori Infection. Gastroenterol Res Pract. 2013;2013:643109. doi: 10.1155/2013/643109. [PubMed: 23762037]. [PubMed Central: PMC3671525].

2. Zhang FM, Yu CH, Chen HT, Shen Z, Hu FL, Yuan XP, et al. Helicobacter pylori infection is associated with gallstones: Epidemiological survey in China. World J Gastroenterol. 2015;21(29):8912-9. doi: 10.3748/wjg.v21.i29.8912. [PubMed: 26269681]. [PubMed Central: PMC4528034].

3. Sabbaghian MS, Ranaudo J, Zeng L, Alongi AP, Perez-Perez G, Shamamian P. Identification of Helicobacter spp. in bile and gallbladder tissue of patients with symptomatic gallbladder disease. HPB (Oxford). 2010;12(2):129-33. doi: 10.1111/j.1477-2574.2009.00148.x. [PubMed: 20495657]. [PubMed Central: PMC2826671].

4. Lee JW, Lee DH, Lee JI, Jeong S, Kwon KS, Kim HG, et al. Identification of Helicobacter pylori in Gallstone, Bile, and Other Hepatobiliary Tissues of Patients with Cholecystitis. Gut Liver. 2010;4(1):60-7. doi: 10.5009/gnl.2010.4.1.60. [PubMed: 20479914]. [PubMed Central: PMC2871607].
5. Monstein HJ, Jonsson Y, Zdolsek J, Svanvik J. Identification of Helicobacter pylori DNA in human cholesterol gallstones. Scand J Gastroenterol. 2002;37(1):112-9. doi: 10.1080/003655202753387455. [PubMed: 11843027]

6. Takahashi Y, Yamamichi N, Shimamoto T, Mochizuki S, Fujishiro M, Takeuchi C, et al. Helicobacter pylori infection is positively associated with gallstones: a large-scale cross-sectional study in Japan. J Gastroenterol. 2014;49(5):882-9. doi: 10.1007/s00535-013-0832-z. [PubMed: 23736795].

7. Stathopoulos P, Zundt B, Spelsberg FW, Kolligs L, Diebold J, Goke B, et al. Relation of gallbladder function and Helicobacter pylori infection to gastric mucosa inflammation in patients with symptomatic cholecystolithiasis. Digestion. 2006;73(2-3):69-74. doi: 10.1159/000092746. [PubMed: 16641551].

8. Deeba J, Sanjay S, Abida M, Athar K. Helicobacter pylori in gallbladder disease. Biomed Res. 2010;21:437-40.

9. Abro AH, Haider IZ, Ahmad S. Helicobacter pylori infection in patients with calcular cholecystitis: a hospital based study. J Ayub Med Coll Abbottabad. 2011;23(1):30-3. [PubMed: 22830140].

10. Fikry AA. Helicobacter pylori infection in patients with chronic calcular cholecystitis a cross- sectional study. J Surg. 2014;2(4). doi: 10.11648/j.js.20140204.12.

11. Glenn F. Acute cholecystitis. Surg Gynecol Obstet. 1976;143(1):56-60. [PubMed: 936049].

12. Schirmer BD, Winters KL, Edlich RF. Cholelithiasis and cholecystitis. J Long Term Eff Med Implants. 2005;15(3):329-38. doi: 10.1615/jlongtermeffmedimplants.v15.i3.90. [PubMed:16022643].

13. Teilum D, Christoffersen IL. [Acute cholecystitis with and without gallstones. The frequency of surgical interventions in Frederiksberg during the period 1978-1988]. Ugeskr Laeger.1990;152(25):1827-8. [PubMed: 2363219].

14. Casper M, Lammert F. [Gallstone disease: basic mechanisms, diagnosis and therapy]. Praxis (Bern 1994). 2011;100(23):1403-12. doi: 10.1024/1661-8157/a000721. [PubMed: 22086379].

15. Supe A. Asymptomatic gall stones-revisited. Trop Gastroenterol. 2011;32(3):196-203. [PubMed: 22332335].

16. Chang YR, Jang JY, Kwon W, Park JW, Kang MJ, Ryu JK, et al. Changes in demographic features of gallstone disease: 30 years of surgically treated patients. Gut Liver. 2013;7(6):719-24. doi: 10.5009/gnl.2013.7.6.719. [PubMed: 24312714]. [PubMed Central: PMC3848536].

17. Rokkas T, Simsek I, Ladas S. Helicobacter pylori and non-malignant diseases. Helicobacter. 2007;12 Suppl 1:20-2. doi: 10.1111/j.15235378.2007.00531.x. [PubMed: 17727456].

18. Hashemi MR, Rahnavardi M, Bikdeli B, Dehghani Zahedani M. H pylori infection among 1000 southern Iranian dyspeptic patients. World J Gastroenterol. 2006;12(34):5479-82. doi: 10.3748/wjg.v12.i34.5479. [PubMed: 17006984]. [PubMed Central: PMC4088229].

19. Massarrat S, Saberi-Firoozi M, Soleimani A, Himmelmann GW, Hitzges M, Keshavarz H. Peptic ulcer disease, irritable bowel syndrome and constipation in two populations in Iran. Eur J Gastroenterol Hepatol. 1995;7(5):427-33. [PubMed: 7614105]

20. Lane JA, Murray LJ, Noble S, Egger M, Harvey IM, Donovan JL, et al. Impact of Helicobacter pylori eradication on dyspepsia, health resource use, and quality of life in the Bristol helicobacter project: randomised controlled trial. BMJ. 2006;332(7535):199-204. doi: 10.1136/bmj.38702.662546.55. [PubMed: 16428249]. [PubMed Central: PMC1352048].

21. Moayyedi P, Soo S, Deeks J, Delaney B, Harris A, Innes $M$, et al. Eradication of Helicobacter pylori for non-ulcer dyspepsia. Cochrane Database Syst Rev. 2001;(1). CD002096. doi: 10.1002/14651858.CD002096. [PubMed: 11279751]. 